\title{
Predicting Pre-Eclampsia \& Fetal Growth Restriction through Second Trimester Uterine Artery Doppler Sonography: An Indian experience
}

\author{
Padmalatha VV, Rao PSS, Susan Abraham, Asha Thomas
}

\section{Introduction}

Over the past 4 decades, the capabilities of ultrasound flow imaging in medical management, especially in obstetrics, have increased enormously, with color flow imaging now in commonplace and facilities such as 'power' or 'energy' Doppler providing new ways of imaging flow ${ }^{1,2}$. With such versatility, it is tempting to employ the technique for ever more demanding applications and to try to measure increasingly subtle changes in the maternal and fetal circulations ${ }^{3}$. Pre-eclampsia and intrauterine growth restriction remain important causes of maternal and perinatal morbidity and mortality ${ }^{4,5}$. Accurate prediction of pre-eclampsia and intrauterine growth restriction is crucial to allow judicious allocation of resources for monitoring and preventive treatment to improve maternal and perinatal outcomes ${ }^{6}$. Alterations in waveforms in the uterine artery are associated with the development of pre-eclampsia and intrauterine growth restriction. However, the findings from various studies have not been consistent nor provided clear guidelines for obstetrical management ${ }^{7,8}$. The performance of uterine artery Doppler velocimetry as a screening test seems to depend on the prevalence of the adverse outcome in the studied population and whether the adverse outcomes are assessed individually or collectively. In the light of these controversies and conflicting recommendations, there seems to be a need for more data from properly designed research studies. There is also a need to clarify the specific parameters measured in the Doppler procedure in order that the predictions can be simpler for use in common practice by obstetricians. Further, most studies are done in developed countries and there are hardly any studies examining Doppler ultrasonography critically in developing world such as in India, where pre-eclampsia and fetal growth restrictions are quite common. In this paper, experiences in the use of Doppler during the second trimester of women attending a multispecialty hospital in the outskirts of Bangalore city in Karnataka state, India, are presented with a brief discussion on future research ideas.

\section{Material \& Methods}

The study was carried out at Bangalore Baptist Hospital(BBH), in Karnataka State, a private multispecialty hospital, well known for quality care. A random sample of 217 women with singleton pregnancy between 20-24 weeks were selected and subjected to uterine artery Doppler along with the routine morphology scan from April 2002 to March 2003. The study consisted of high and low risk patients where high risk included previous pregnancies with pregnancy induced hypertension or pre-eclampsia, small for gestational age baby, or poor perinatal outcome. Patients with preexisting hypertension and anomalous babies were excluded from the study.

Procedure: With the transducer in the longitudinal plane, the external iliac artery is visualized at pelvic sidewall with color Doppler. The transducer is then angled medially towards the uterine arteries where they cross the external iliac arteries. Four different waveforms were obtained from each uterine artery and the average was taken on each side. The procedure took 5 minutes in addition to the 12-15 minutes required for biometry and morphology. These patients were followed up till delivery and the details of pregnancy events, labour and delivery and neonatal outcome were noted.

Record review was done using a formatted proforma, which was filled up. The follow up details were obtained from the labour room and medical records. The results of the test were not revealed to the patient or the clinician and no action was taken based on the Doppler results. The study was accepted by the ethics committee of our hospital. The outcome measures studied were Preeclampsia, SGA $<5^{\text {th }}$ centile, SGA $<10^{\text {th }}$ centile, any of these conditions requiring delivery before 34 weeks.

The parameters analysed were the 90th centile, 95th centile, 2 standard deviations applied on the right and left PI, RI and S/D also any of the parameter and more than 3 of the parameter being positive. In addition, any notch being present (bilateral or unilateral) present was taken as positive predictor. The validity of Doppler as predictor was tested using sensitivity, specificity, positive and negative predictive values and percentages of false positive and false negative for the outcome measures. The results were analyzed using the summary receiver-operating characteristic curve, by plotting the true positive rate (sensitivity) vs. false positive rate (1Specificity) by taking the values for various cutoffs (90th and 95th percentiles, 2 standard deviations, standard 
cutoffs) for various parameters. The curve with greatest area under it represented the best predictor for the disease. The other outcome measure observed was nonproteinuric pregnancy induced hypertension, in high risk and low risk patients.

\section{Results:}

The Mean(SD) age of women was 24(4)years, the gestational age at the time of assessment was 22.6(1.2)weeks, height and weight were $153(7) \mathrm{cm}$ and $54.2(10.1) \mathrm{kg}$ respectively, and the systolic and diastolic blood pressures were 110(7) and 72(7). The Mean(SD) Pulsatility Index on the right was $0.85(0.35)$ and $0.88(0.33)$ on the left. The RI was $0.53(0.12)$ on the right and $0.54(0.10)$ on the left; the S/D on the right was 2.23(0.79) and on the left it was 2.28(0.70). The Mean(SD) ultrasonic age was 22.2(0.7)weeks, the Gestational Age at delivery was $38.2(1.5)$ weeks, and the Birthweight was $2.83(0.43) \mathrm{kg}$.

The Complications noted in the study are presented in Table 1 .

TABLE 1

Two patients had intra uterine death. Both of them were nulliparous i.e., low risk. Among them 1 patient had high Doppler indices with a unilateral notch and had intrauterine death at 35 weeks with a small for gestational age baby of $1.27 \mathrm{Kg}$ but there was no pre-eclampsia or pregnancy induced hypertension. The other patient had normal Doppler no pre-eclampsia and low birth weight of $2.3 \mathrm{Kg}$ at 39 weeks. There was 1 case of maternal death with high Doppler at the time of scan. She had severe pre-eclampsia and had caesarian section for PROM and died with pulmonary embolism. There were no smokers or alcoholics among the study population. There were no cases of antepartum haemorrhage or eclampsia.

The validity of Doppler ultrasonography for predicting Preeclampsia and PIH based on the local cut-offs(BBH) which are the Doppler values above the $95^{\text {th }}$ centile and the standard cutoffs from previous studies ${ }^{9-11}$, is shown in Table 2.

TABLE 2

Diastolic notch as a single parameter is the best indicator with highest sensitivity and positive predictive value. However the combination of parameters is the best indicator. $95^{\text {th }}$ percentile gives better ratios. Taking the standard cut-off for the parameters from studies reduces the specificity and positive predictive value though increases the sensitivity. Doppler is better tool for predicting severe form of the disease i.e. preeclampsia (SE80) rather than the milder PIH (SE-18).

The efficacy of Doppler sonography for predicting $\mathrm{SGA}<5^{\text {th }}$ and $10^{\text {th }}$ percentiles are given in Table 3 .

TABLE 3

Diastolic notch as a single parameter is the best indicator with highest sensitivity and positive predictive value. RI has sensitive and specificity similar to notch. However the combination of parameters is the best indicator. $95^{\text {th }}$ percentile gives better ratios. Taking the standard cut-off reduces the specificity and positive predictive value though increases the sensitivity. The sensitivities of Doppler for SGA are lesser than for preeclampsia.

The Summary Receiver Operating Characteristic Curves for Preeclampsia, $\mathrm{SGA}<5^{\text {th }}$ centile and SGA $<10^{\text {th }}$ centile are displayed in figures I, II and III respectively

FIGURE I

FIGURE II

FIGURE III

ROC curves show that Doppler is a better predictor for Pre-eclampsia than fetal growth restriction. Since the ROC of SGA $<10$ taken as cut-off for fetal growth restriction, is more linear compared to SGA $<5$, Doppler is better predictor of severe growth restriction. Notch could not be plotted as it has a single value (Present / Absent).

Comparison between HighRisk and LowRisk pregnancies with Notch as Predictor is shown in Table 4.

TABLE 4

Doppler predicts Pre-eclampsia better in high risk patients and since the prevalence is more in the high risk it may be more useful in high risk cases. Doppler also predicts fetal growth restriction better in high risk patients and since the prevalence is more in the high risk it may be more useful in high risk cases.

\section{Discussion}

Over the past two decades, several investigators have explored the validity of Uterine artery Doppler flow velocity waveforms as predictors of pre-eclampsia, fetal growth restriction, and adverse perinatal outcomes ${ }^{12}$. Research has also examined if predictive powers can be enhanced by recording early diastolic notch, bilateral 
notches, increased pulsality indices ${ }^{2,7,8}$ Yet, there has been no consensus on several aspects of Doppler ultrasonography in terms of the best time for assessment, the optimal outcome parameters, cut-off thresholds to obtain maximum predictive powers, and relationship of prediction to prevalence of the adverse events ${ }^{13,14}$. The findings of the present study done several years ago in south India seem still valid in terms of the timing, parameters and optimal screening efficacies(Table 1 and 2).

For example, the sensitivity of Doppler by PI $>95^{\text {th }}$ centile and unilateral notch has sensitivities for preeclampsia especially the severe disease requiring delivery before 37 weeks than mild preeclampsia or non proteinuric hypertension. The positive predictive values are better if combination of parameters show abnormality than if any one parameter taken ${ }^{12,15}$. Extrapolating the results taking the standard reference values has shown to have higher sensitivities though reduces the specificity and positive predictive values. This may be due to different characteristics of the study population. Hence there is a need to generate the reference ranges from the population in question to improve the validity of the test ${ }^{16}$.

To a practicing obstetrician, Doppler provides a panorama of parameters, which needs to be judiciously considered taking into account the high risk profile of the mother as well as the implications of false predictive values. Several investigators have suggested that diastolic notch in the uterine artery as a single parameter is better than the individual Doppler indices ${ }^{15,17,18}$, while others are more in favour of using the PI ${ }^{12}$, ${ }_{19}$. Given the technological improvements in the Doppler hardware and software ${ }^{20}$, ultimately the ability to measure accurately the increased impedance to uterine artery flow in both high risk and low risk pregnancies becomes crucial to predict the risk for subsequent development of pre-eclampsia and fetal growth restriction.

The findings from this research show that women with normal impedance to flow in the uterine arteries constitute a group that have a low risk (negative predictive value for pre-eclampsia is $99 \%$ and for SGA $<5$ th percentile is 93\%) of developing obstetric complications related to Uteroplacental insufficiency, as observed by others ${ }^{14,21}$.

In the present study and other studies $3,7,22$ indicate that Doppler is a better tool for high risk women. The negative predictive values being high, Doppler can reduce the anxiety and burden on high risk women, as women with normal Doppler are unlikely to develop preeclampsia, and severe FGR ${ }^{14}$.

In the light of the findings from various research studies, not all consistent, there has been much debate on whether Doppler ultrasonography should be routinely used in obstetrical practice ${ }^{23-26}$. Both pre-eclampsia and fetal growth restriction being of grave nature and of higher incidence in the Indian population, the inclusion of Doppler which takes another 5 minutes in trained hands with the anomaly scan may help to identify a group of women who may be referred to higher centers for further antenatal work up and the normal Doppler women may safely follow in low resource settings as well. Whether Doppler findings along with other investigations can improve the prediction has been studied but no firm conclusions could be drawn ${ }^{27-29}$. Being a noninvasive procedure has its advantages and maximizing its potential should be the focus of further research.

\section{Conclusions}

A combination of parameters is the best indicator for prediction of Pre-eclampsia and fetal growth restriction. Diastolic notch in the uterine artery as a single parameter is better than the individual Doppler indices. Increased impedance to uterine artery flow in both high risk and low risk pregnancies is associated with the risk for subsequent development of Pre-eclampsia and fetal growth restriction and it is a better predictor for high-risk patients. Women with normal impedance to flow in the uterine arteries constitute a group that have a low risk (negative predictive value for pre-eclampsia is $99 \%$ and for $\mathrm{SGA}<5^{\text {th }}$ percentile is $93 \%$ ) of developing obstetric complications related to Uteroplacental insufficiency. Abnormal Doppler is better predictor of Preeclampsia(sensitivity $60 \%$ ) than fetal growth restriction ( sensitivity $26 \%$ ). Reference ranges taken from the study population are better indicators than those from other studies. Uterine artery Doppler may be included in hospitals with facilities and infrastructure to identify a group of patients at risk of developing Pre-eclampsia or fetal growth restriction. Further studies have to be done to examine its potential as a screening tool.

Table 1 - Complications during pregnancy

\begin{tabular}{ll}
\hline Outcome & No of Patients \\
\hline & 5 \\
PET & 11 \\
PIH & 19 \\
SGA $<5^{\text {th }}$ & 28 \\
SGA $<10^{\text {th }}$ & 16 \\
Oligohydramnios & 11 \\
Operative Delivery for Fetal distress & 20 \\
Inductions for PIH/Oligohydramnios & 2 \\
Apgar $\leq 5$ and 7 & 2 \\
IUD & 3 \\
Any of above Requiring Del $\leq 34$ weeks & \\
\hline
\end{tabular}


Predicting Pre-Eclampsia \& Fetal Growth Restriction through Second Trimester Uterine Artery

Table 2 : Efficacy of Uterine Artery Doppler Sonography for Predicting Preeclampsia and PIH

\begin{tabular}{|c|c|c|c|c|c|c|c|c|c|c|c|}
\hline \multirow[t]{2}{*}{ Outcome } & \multirow[t]{2}{*}{ Predictor } & \multicolumn{5}{|c|}{ BBH Cut off for predictor } & \multicolumn{5}{|c|}{ Standard cut off for predictor } \\
\hline & & Cut-off & $\mathrm{SE}$ & SP & PPV & NPV & Cut-off & SE & SP & PPV & NPV \\
\hline \multirow{6}{*}{$\begin{array}{l}\text { Preeclamsia for } \\
95 \text { th Percentile } \\
\text { cut off } \\
\mathrm{N}=5 \text {, } \\
\text { Prevalence = } \\
2.3 \%\end{array}$} & PI & 1.51 & 60 & 92 & 16 & 99 & $1.60^{9}$ & 60 & 94 & 20 & 99 \\
\hline & RI & 0.73 & 60 & 92 & 16 & 99 & $0.58^{10}$ & 100 & 56 & 5 & 100 \\
\hline & $\mathrm{S} / \mathrm{D}$ & 3.63 & 60 & 92 & 15 & 99 & $2.50^{11}$ & 80 & 68 & 6 & 99 \\
\hline & Notch & Yes & 80 & 94 & 25 & 100 & Yes & 80 & 94 & 25 & 100 \\
\hline & Any & & 80 & 86 & 12 & 99 & & 100 & 54 & 5 & 100 \\
\hline & Combination & & 60 & 98 & 38 & 99 & & 80 & 92 & 19 & 99 \\
\hline \multirow{6}{*}{$\begin{array}{l}\text { PIH for } \\
\text { Percentile } \\
\text { off } \\
\mathrm{N} \quad= \\
\text { Prevalence } \\
5.1 \%\end{array}$} & PI & & 18 & 92 & 11 & 95 & & & & & \\
\hline & RI & & 27 & 92 & 16 & 96 & & & & & \\
\hline & $\mathrm{S} / \mathrm{D}$ & & 18 & 91 & 10 & 95 & & & & & \\
\hline & Notch & & 18 & 93 & 13 & 96 & & & & & \\
\hline & Any & & 36 & 86 & 12 & 96 & & & & & \\
\hline & Combination & & 9 & 97 & 13 & 95 & & & & & \\
\hline
\end{tabular}

SE - Sensitivity, SP - Specificity, PPV-Positive Predictive value, NPV - Negative Predictive Value, Any - Any 1 of 8 parameters (bilateral RI, PI, S/D, Notch) abnormal, Severe - More than 3 of 8 parameters abnormal. PI, $R I, S / D$, Notch are taken positive if either right or left is abnormal.

Table3: Efficacy of Uterine Artery Doppler Sonography for Predicting SGA $<5^{\text {th }} \boldsymbol{\&}<10^{\text {th }}$ Percentile

\begin{tabular}{|c|c|c|c|c|c|c|c|c|c|}
\hline \multirow{2}{*}{ Outcome } & \multirow{2}{*}{ Predictor } & \multicolumn{4}{|c|}{ BBH Cut off for predictor } & \multicolumn{4}{|c|}{ Standard cut off for predictor } \\
\hline & & SE & SP & PPV & NPV & SE & SP & PPV & NPV \\
\hline \multirow{6}{*}{$\begin{array}{l}\text { SGA }<\mathbf{5}^{\text {th }} \text { Vs } \\
95^{\text {th }} \\
\text { Predictors, } \\
\text { for } \\
\text { Prevalence } \\
=8.8 \%\end{array}$} & PI & 21 & 92 & 21 & 92 & 26 & 89 & 19 & 93 \\
\hline & RI & 26 & 93 & 26 & 93 & 58 & 56 & 11 & 93 \\
\hline & $\mathrm{S} / \mathrm{D}$ & 21 & 92 & 20 & 92 & 53 & 69 & 14 & 94 \\
\hline & Notch & 26 & 94 & 31 & 93 & 26 & 94 & 31 & 93 \\
\hline & Any & 37 & 87 & 21 & 93 & 63 & 54 & 12 & 94 \\
\hline & Combination & 21 & 98 & 50 & 93 & 32 & 92 & 29 & 93 \\
\hline \multirow{6}{*}{$\begin{array}{l}\text { SGA }<\text { 10th Vs } \\
95 \text { th for } \\
\text { Predictors, } \\
\mathrm{N} \quad= \\
\text { Prevalence } \\
=12.9 \%\end{array}$} & PI & 18 & 93 & 26 & 88 & 25 & 90 & 27 & 89 \\
\hline & RI & 18 & 93 & 26 & 88 & 61 & 57 & 17 & 91 \\
\hline & $\mathrm{S} / \mathrm{D}$ & 14 & 92 & 20 & 88 & 57 & 71 & 23 & 92 \\
\hline & Notch & 21 & 95 & 38 & 89 & 21 & 95 & 38 & 89 \\
\hline & Any & 32 & 87 & 27 & 90 & 64 & 55 & 17 & 91 \\
\hline & Combination & 14 & 98 & 50 & 89 & 25 & 93 & 33 & 89 \\
\hline
\end{tabular}

SE - Sensitivity, SP - Specificity, PPV-Positive Predictive value, NPV-Negative Predictive Value, Any - Any 1 of 8 parameters (bilateral RI, PI, S/D, Notch) abnormal,Severe - More than 3 of 8 parameters abnormal. PI, RI, S/D, Notch are taken positive if either right or left is abnormal.

Table 4: Comparison between HighRisk and LowRisk pregnancies with Notch as Predictor

\begin{tabular}{|l|l|l|l|}
\hline & Prevalence & Sensitivity & Specificity \\
\hline HighRisk & 3 & 100 & 95 \\
\hline LowRisk & 2 & 75 & 94 \\
\hline
\end{tabular}

Fig I: ROC curve for Preeclampsia

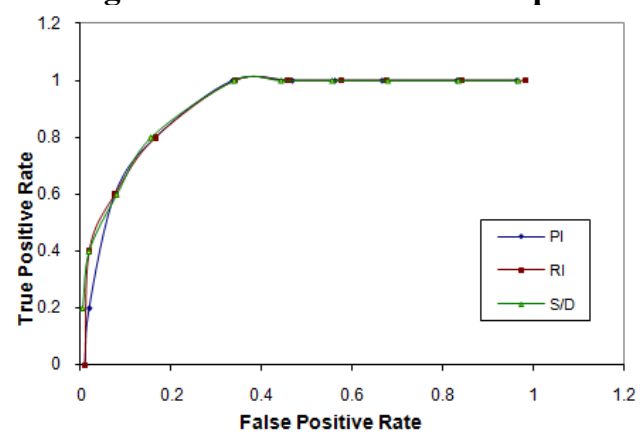


Fig II: ROC curve for SGA $<5$ th centile

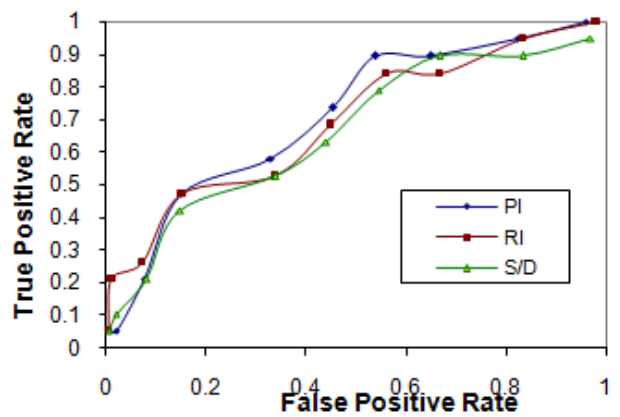

Fig III: ROC curve of SGA < 10th centile

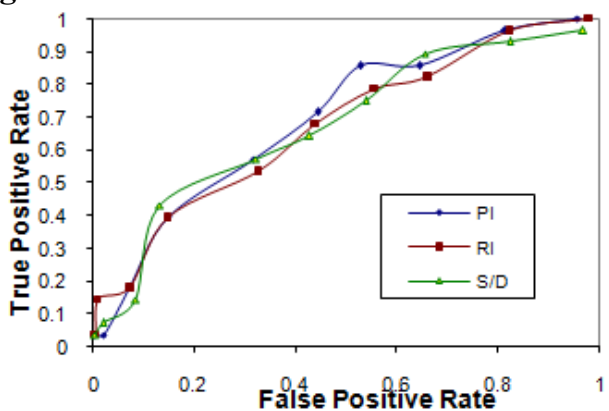

Acknowledgements:

We thank the management of Bangalore Baptist hospital for allowing us to conduct the study and all the patients who willfully accepted to undergo the dopplers and be a part of the study.

\section{References}

[1]. Luria O, Barnea O, Shalev J, Barkat J, Kovo M, Bar J (2012) Two-dimensional and three-dimensional Doppler assessment of fetal growth restriction with different severity and onset. Prenat,Diag.17:1-7

[2]. Jodicke C, Maulik D, Singh P, Heitmann E(2012) Role of ultrasound in pre-eclampsia. Minerva ginecol.64:293-308

[3]. Capucci R, Pivato E, Carboni S, Mossuto E, Castellino G, Padovan M, Govoni M,Marci R, Patella A (2011). J.Prenat.Med .5: 548

[4]. Sibai B, Dekker G, Kupferminc M. Pre-eclampsia. Lancet2005;365:785-99. [PubMed]

[5]. Khan KS, Wojdyla D, Say L, et al. WHO analysis of causes of maternal death: a systematic review. Lancet2006;367:1066-74. [PubMed]

[6]. Harbord RM, Deeks JJ, Egger M, Whiting P, Sterne JA (2007) Review Bivariate analysis if sensitivity and specificity produces informative summary measures in diagnostic reviews.Biostatistics.8: 239-251

[7]. Pilalis A, Souks AP, Antsaklis P, Daskalakis G, Papantoniou N, Mesogitis S,Antkalis A.(2007) How useful is uterine artery Doppler flow velocimetry in the prediction of pre-eclampsia, uterine growth retardation and perinatal death ? An Overview. Ultrasound Obstet.Gynecol.29:135-40

[8]. Pedrosa AC and Matias A (2011)Screening for pre-eclampsia: a systematic review of tests combining uterine artery Doppler with other markers. J. Prenat. Med.39:619-35

[9]. Papageorghiou AT, Yu CK, Bindra R, Pandis G, Nicolaides KH; Fetal Medicine Foundation Second Trimester Screening Group Multicenter screening for pre-eclampsia and fetal growth restriction by transvaginal uterine artery Doppler at 23 weeks of gestation. Ultrasound Obstet Gynecol. 2001 Nov;18(5):441-9.

[10]. Campbell S, Diaz-Recasens J, Griffen DR et al., (1983) New Doppler technique for assessing uteroplacental blood flow. Lancet 1:675-77.

[11]. Oliver Irion, Jacques Masse, Jean-Claude forest, Jean-Marie Moutquin. Prediction of pre-eclampsia, low birth weight for gestation and prematurity by uterine artery blood flow velocity waveforms analysis in low risk nulliparous women. British Journal of Obstetrics and Gynecology. April 1998. Vol. 105 pp 402-425.

[12]. Cnossen JS, Morris RK, ter Riet G,Mol BWJ, van der Post JAM, Coomarasamy Zwinderman AH, Robson SC, Bindels PJE, Kleijnen J, Khan KS (2008).Use of uterine artery Doppler ultrasonography to predict pre-eclampsia and intrauterine growth restriction: a systematic review and bivariable meta-analysis. Canadian Medical Assoc. J. 178:701-711

[13]. Papageorghiou AT, Yu CK, Nicolaides KH. The role of uterine artery Doppler in predicting adverse pregnancy outcome. Best Pract Res Clin Obstet Gynaecol. 2004;18:383-396.

[14]. Pongrojpaw D, Chanthasenanont A, Nanthakomon T(2010) Second Trimester uterine artery Doppler screening in prediction of adverse pregnancy outcome in high risk women. J Med Assoc Thai. 2010 Dec;93 Suppl 7:S127-30

[15]. Zimmermann P, Eirio V, Koskinen J, Kujanscu E, Ranta T(1997). Doppler assessment of uterine and uteroplacental circulation in the second trimester in pregnancies at high risk for pre-eclampsia and / or fetal growth restriction: comparisons and correlation between difference Doppler parameters ultrasound Obstet. Gynecol May; 9(5): 330-8.

[16]. Napolitano R, Santo S, D'Souza R, Bhide A, Thilaganathan B(2010) Sensitivity of higher, lower and mean second-trimester uterine artery Doppler resistance indices in screening for pre-eclampsia. Ultrasound Obstet Gynecol. 36:573-6.

[17]. Bower S, Bewley Susan, Campbell S. Improved prediction of pre-eclampsia by two stage screening of uterine arteries using the early diastole notch and color Doppler imaging. Obstet Gynecol 1993; 82:78-83.

[18]. Antsaklis A, Daskalakis G, Tzortzis E, Michalas S. The effect of gestational age with placental location on the prediction of preeclampsia by uterine artery Doppler velocimetry in low risk nulliparous women. Unilateral Obstet Gynecol 2000; 16:635-9.

[19]. Albaiges G, Missfelder- Lobos H, Lees C, Parra M, Nicolaides KH. One-stage screening for pregnancy complications by color Doppler assessment of the uterine arteries at 23 weeks gestation. Obstet Gynecol 2000 in press.

[20]. Dev M (2005) Doppler Ultrasound in Obstetrics \& Gynecology. Springer

[21]. Kurdi W, Campbell S, Aquilina J, England P, Harrington K. The role of color Doppler imaging of the uterine arteries at 20 weeks gestation in stratifying antenatal care. Ultrasound Obstet Gynecol 1988;12:339-45.

[22]. Chien PF, Arnott N, Gordon A, et al (2000). How useful is uterine artery Doppler flow velocimetry in the prediction of preeclampsia, intrauterine growth retardation and perinatal death ? An Overview... BJOG.107:196-208

[23]. North RA, Ferrier C, Long D, Townend K, Kincaid-smith F. Uterine artery Doppler flow velocity waveforms in the second trimester for the prediction of pre-eclampsia and fetal growth retardation. Obstet Gynecol 1994; 83:378-86.

[24]. Bewley Susan, Cooper Derek, Campbell S. Doppler investigations of uteroplacental blood flow resistance in the second trimester: a screening study for pre-eclampsia and intrauterine growth retardation. Br.J.Obstetrics \& Gynecology 1991:98:871-879. 
[25]. DuBose TJ, Baker AL (2009). "Confusion and Direction in Diagnostic Doppler Sonography". Journal of Diagnostic Medical Sonography 25 (3): 173. doi: $10.1177 / 8756479309335681$

[26]. Yu CK, Khouri O, Onwudiwe N, Spiliopoulos Y, Nicolaides KH. Fetal Medicine Foundation Second-Trimester Screening Group. Prediction of pre-eclampsia by uterine artery Doppler imaging: relationship to gestational age at delivery and small-for-gestational age. Ultrasound Obstet Gynecol. 2008;31:310-313.

[27]. Usha Krishna, DK Tank, Shirish Daftary(2001) Pregnancy at Risk current concepts. 4th ed. 257:285

[28]. Giguère Y, Charland M, Bujold E, Bernard N, Grenier S, Rousseau F, Lafond J, Légaré F, Forest JC(2010) Combining biochemical and ultrasonographic markers in predicting preeclampsia: a systematic review. Clin Chem. 56: 361-75.

[29]. Ghosh SK, Raheja S, Tuli A, Raghunandan C, Agarwal S.(2012)Combination of uterine artery Doppler velocimetry and maternal serum placental growth factor estimation in predicting occurrence of pre-eclampsia in early second trimester pregnancy: a prospective cohort study. Eur J Obstet Gynecol Reprod Biol. 161(2):144-51 